\title{
Structural Characterization of Supported Platinum Carbonyl Clusters by X-ray Absorption Spectroscopy
}

\author{
Kanjiro Torigoe, ${ }^{\dagger, \dagger}$ Hynd Remita, ${ }^{\dagger}$ Georgette Picq,,${ }^{\dagger}$ Jacqueline Belloni,,${ }^{\dagger}$ and \\ Dominique Bazin $\$$ \\ Laboratoire de Chimie Physique, Bât. 350, Université PARIS-XI, 91405 Orsay Cedex, France, and \\ Laboratoire pour l'Utilisation du Rayonnement Electromagnétique, Bât. 210, Université PARIS-XI, \\ 91405 Orsay Cedex, France
}

Received: February 18, 2000; In Final Form: May 8, 2000

\begin{abstract}
The Chini-type Pt carbonyl clusters $\left(\left[\mathrm{Pt}_{3}(\mathrm{CO})_{6}\right]_{n}{ }^{2-}, n=4,5,6\right)$ and other CO-stabilized Pt clusters were synthesized by $\gamma$-radiolysis, and their structures, when supported on carbon and $\alpha$-alumina, were investigated by X-ray absorption spectroscopy (XAS). It was found that the stacking prismatic structure of triangular units in Chini clusters was transformed, when supported on carbon, into another structure in which the trimeric units are conserved but are now arranged in a planar monolayer. Some carbonyl groups remain to be ligated to Pt atoms under nitrogen atmosphere. However, on contact with the air, the carbonyl clusters are partially transformed into fcc Pt clusters. When supported on $\alpha$-alumina, a more important structural evolution of supported clusters with a size growth is observed. Two groups of platinum clusters are obtained: the first one with a $\mathrm{Pt}-\mathrm{Pt}$ distance corresponding to the intratriangular distance present in the Chini clusters, and the second one constituted of larger fcc clusters with a Pt-Pt distance close to the bulk one.
\end{abstract}

\section{Introduction}

During the past decade, platinum $(\mathrm{Pt})$ clusters have been extensively studied ${ }^{1-3}$ particularly as active catalysts for application in low-temperature fuel cell systems such PEMFC or PAFC (protonic exchange membrane and phosphoric acid fuel cells, respectively). Among them, supported $\left[\mathrm{Pt}_{3}(\mathrm{CO})_{6}\right]_{n}{ }^{2-}$ clusters were soon recognized as very attractive materials. ${ }^{4-6}$ They were first synthesized by Chini et al. ${ }^{4,5}$ in methanol or tetrahydrofuran (THF) solution by the reduction of $\mathrm{Pt}^{\mathrm{IV}}$ chloride in basic solution in the presence of carbon monoxide. Since then, several methods for preparing such supported catalysts have been proposed. As shown by X-ray diffraction crystal analysis, the Chini clusters display a twisted prismatic structure composed of $n$ stacking triangular units stabilized by $\mathrm{CO}$ ligands ${ }^{4}$ (atomic distances are indicated in Figure 1) and doubly negative charge as a whole. Their electronic structures have been theoretically studied. ${ }^{7-9}$ De Mallmann et al. ${ }^{10}$ and Kubelková et al. ${ }^{11}$ have synthesized the Chini clusters in ion-exchanged zeolites. A correlation was found between the basicity of the zeolite and the cluster nuclearity. ${ }^{10-14}$ The Ichikawa group observed a high catalytic activity of the Chini clusters $\left[\mathrm{Pt}_{3}(\mathrm{CO})_{6}\right]_{n}{ }^{2-}(n=3-5)$ prepared in $\mathrm{NaY}$ and $\mathrm{NaX}$ zeolites ${ }^{13}$ for the $\mathrm{CO}+\mathrm{NO}$ reaction or synthesized in the confined mesoporous channels of FSM-16 for the hydrogenation of ethene and 1,3-butadiene ${ }^{14}$ or for the water gas shift reaction. ${ }^{15}$ The adsorbed clusters were characterized by in situ Fourier transform infrared (FTIR) and extended X-ray absorption structure (EXAFS) methods. ${ }^{13-15}$ Other classes of CO-stabilized $\mathrm{Pt}$ clusters, such as polyhedral $\left[\mathrm{Pt}_{24}(\mathrm{CO})_{30}\right]^{n-},\left[\mathrm{Pt}_{26}(\mathrm{CO})_{32}\right]^{n-}$, and $\left[\mathrm{Pt}_{38}(\mathrm{CO})_{44}\right]^{n-}(n=0-10)$, are also known. ${ }^{5,16,17}$

* To whom correspondence should be addressed. Fax: 00331691561 88. E-mail: jacqueline.belloni@1pcr.u-psud.fr.

$\dagger$ Laboratoire de Chimie Physique.

§ Laboratoire pour l'Utilisation du Rayonnement Electromagnétique.

$\doteqdot$ Present address: Department of Applied Chemistry, Science University of Tokyo, 1-3, Kagurazaka, Shinjuku-ku, 162-8601 Tokyo, Japan.

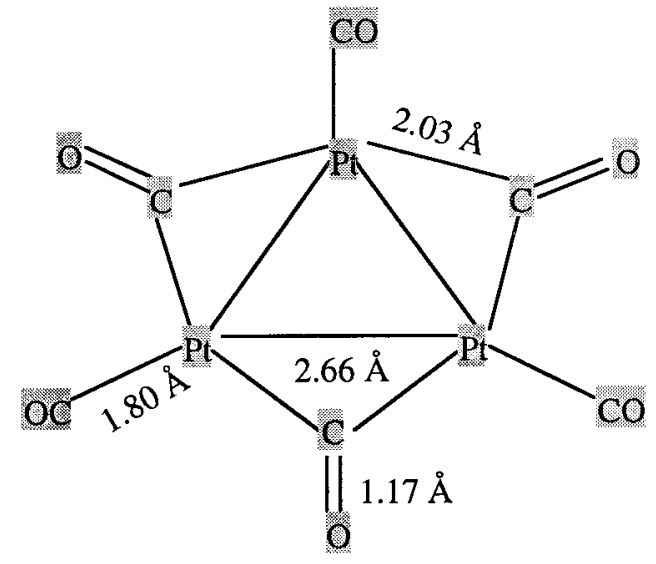

Figure 1. $\mathrm{Pt}_{3}(\mathrm{CO})_{6}$ triangular unit in the molecular structure of $\mathrm{Pt}$ carbonyl cluster dianions $\left[\mathrm{Pt}_{3}(\mathrm{CO})_{6}\right]_{n}{ }^{2-}$ (Chini clusters). Stacking of $\mathrm{Pt}_{3}(\mathrm{CO})_{6}$ units; $R(\mathrm{Pt}-\mathrm{Pt})$ (intertriangular distance between stacked units) $=3.08-3.10 \AA$ for $n=3-6)$. The interatomic distances are taken from the crystal analysis in ref 4 .

In CO-saturated water/2-propanol mixed solvent, $\mathrm{Pt}^{\mathrm{II}}$ or $\mathrm{Pt}^{\mathrm{IV}}$ salts can be radiolytically reduced into the series of Chini clusters by varying the irradiation dose $\mathrm{e}^{18}$ (the higher the dose, the smaller nuclearity is formed) or into other carbonyl clusters by varying the CO/Pt ratio. ${ }^{18,19}$ The reduction of $\mathrm{Pt}$ ions is brought about by a combined effect of $\mathrm{CO}$ and electrons or reducing radicals generated from the solvent radiolysis. Finally, the carbonyl clusters thus prepared in solution can be easily deposited onto supports; for example, onto carbon support up to $60 \mathrm{wt} \%$ without significant aggregation. Transmission electron microscopy (TEM) observations have shown that the particle size of the supported catalyst prepared in this way lies in the $2-3 \mathrm{~nm}$ range. Indeed, these supported Pt clusters have shown high catalytic activity for electrooxidation of methanol in fuel cells. ${ }^{19}$ 
In this paper, structural properties were investigated by X-ray absorption spectroscopy (XAS) ${ }^{20}$ to better understand the specific catalytical activity of Chini clusters. This method is especially useful for the local structure analysis of very small metal particles, ${ }^{21}$ which is difficult by other techniques.

Regarding the structural parameter of nanometric metal particles, it has been already shown that the EXAFS spectroscopy is suitable for very small clusters. The number of first neighbors per atom varies rapidly with the nuclearity in contrast with larger ones, which contain more than a thousand atoms. In that case, the EXAFS modulations become similar to the signal of the Pt metal foil. ${ }^{22}$ The XAS spectroscopy is thus a structural probe, sensitive only to the local order (because of the mean free path term of the photoelectron) around one given type of atom in the medium (well defined by its X-ray absorption edge).

Here, this technique permits evaluation of the influence on the cluster structure and its interaction with the environment of different key parameters relative to the synthesis; namely, the irradiation dose and the Pt salt concentration leading to different Pt carbonyl clusters. Then, the effect of the support carbon and $\alpha$-alumina was studied.

\section{Experimental Section}

Radiolytic Synthesis of Pt Carbonyl Clusters. The $\gamma$-radiolysis of aqueous solutions first generates species issued from water excitation and ionization; that is, hydrated electrons and protons, radicals and molecular products $\left(\mathrm{H}_{2}\right.$ and $\left.\mathrm{H}_{2} \mathrm{O}_{2}\right){ }^{23}$

$$
\mathrm{H}_{2} \mathrm{O} \rightarrow \mathrm{e}_{\mathrm{aq}}{ }^{-}, \mathrm{H}^{+}, \mathrm{H}^{\bullet}, \mathrm{OH}^{\bullet}, \mathrm{H}_{2}, \mathrm{H}_{2} \mathrm{O}_{2}
$$

Likewise, the primary radicals produced by the irradiation of a primary or a secondary alcohol are solvated electrons and protons, $\mathrm{H}^{\bullet}$ radicals and alcohol radicals $\left(\mathrm{R}_{1} \mathrm{R}_{2} \mathrm{C}^{\bullet} \mathrm{OH}\right)$, and molecular products. ${ }^{24} \mathrm{In}$ an acid water/alcohol solvent mixture, solvated electrons are readily scavenged by $\mathrm{H}^{+}$:

$$
\mathrm{e}_{\mathrm{s}}^{-}+\mathrm{H}^{+} \rightarrow \mathrm{H}^{\bullet}
$$

The $\mathrm{H}^{\bullet}$ and $\mathrm{OH}^{\bullet}$ radicals are scavenged by alcohol to produce alcohol radicals:

$$
\begin{gathered}
\mathrm{H}^{\bullet}+\mathrm{R}_{1} \mathrm{R}_{2} \mathrm{CHOH} \rightarrow \mathrm{R}_{1} \mathrm{R}_{2} \mathrm{C}^{\bullet} \mathrm{OH}+\mathrm{H}_{2} \\
\mathrm{OH}^{\bullet}+\mathrm{R}_{1} \mathrm{R}_{2} \mathrm{CHOH} \rightarrow \mathrm{R}_{1} \mathrm{R}_{2} \mathrm{C}^{\bullet} \mathrm{OH}+\mathrm{H}_{2} \mathrm{O}
\end{gathered}
$$

Finally, the metal ions are reduced by $\mathrm{R}_{1} \mathrm{R}_{2} \mathrm{C}^{\bullet} \mathrm{OH}$, which are known to be strong reducing species. Under CO (1 atm), successive steps of reduction, ligation, and aggregation occur, leading to metal carbonyl clusters.

According to a previous work, ${ }^{19}$ the Chini clusters $\left[\mathrm{Pt}_{3}(\mathrm{CO})_{6}\right]_{n}{ }^{2-}$ are synthesized from $\mathrm{K}_{2} \mathrm{PtCl}_{4}$ in methanol or in the mixed solvent water/2-propanol $(1 / 1, \mathrm{v} / \mathrm{v})$ with a concentration of $\mathrm{Pt}$ salt of $10^{-3} \mathrm{M}$. The nuclearity $n$ is controlled by the irradiation dose: ${ }^{18}$ the size of the cluster is adjusted toward smaller $n$ values by increasing the dose. To study the structure of the deposited Chini clusters, three $\left[\mathrm{Pt}_{3}(\mathrm{CO})_{6}\right]_{n}{ }^{2-}$ clusters with $n=4,5$, and 6 were prepared by radiolysis. Samples of $200 \mathrm{~mL}$ of solutions containing $10^{-3} \mathrm{M} \mathrm{K}_{2} \mathrm{PtCl}_{4}$ in equivolumic water/2-propanol mixture were deaerated, saturated by $\mathrm{CO}$ under $1 \mathrm{~atm}$, and irradiated at room temperature by $\gamma$-rays with different doses $\left(3.2,1.6,0.8 \mathrm{kGy}\right.$, respectively, for three $\left[\mathrm{Pt}_{3}(\mathrm{CO})_{6}\right]_{n}{ }^{2-}$ clusters with $n=4,5$, and 6; Table 1 ).

Apart from the Chini clusters, two types of carbonyl clusters $\mathrm{Pt}_{n, \mathrm{CO}}$ derived from Chini clusters ${ }^{18}$ were synthesized at higher
TABLE 1: Conditions of Sample Preparation ${ }^{a}$

\begin{tabular}{lccl}
\hline \multicolumn{1}{c}{ sample } & {$\left[\mathrm{K}_{2} \mathrm{Pt}^{\mathrm{II}} \mathrm{Cl}_{4}\right], \mathrm{M}$} & dose, $\mathrm{kGy}$ & \multicolumn{1}{c}{ support } \\
\hline$\left[\mathrm{Pt}_{3}(\mathrm{CO})_{6}\right]_{4}{ }^{2-} / \mathrm{C}$ & $10^{-3}$ & 3.2 & carbon \\
{$\left[\mathrm{Pt}_{3}(\mathrm{CO})_{6}\right]_{5}{ }^{2-} / \mathrm{C}$} & $10^{-3}$ & 1.6 & carbon \\
{$\left[\mathrm{Pt}_{3}(\mathrm{CO})_{6}\right]_{6}{ }_{6}^{2-} / \mathrm{C}$} & $10^{-3}$ & 0.8 & carbon \\
{$\left[\mathrm{Pt}_{3}(\mathrm{CO})_{6}\right]_{6}^{2-} / \alpha-\mathrm{Al}_{2} \mathrm{O}_{3}$} & $10^{-3}$ & 0.8 & $\alpha$-alumina \\
$\mathrm{Pt}_{n, \mathrm{CO}} / \mathrm{C}$ & $2 \times 10^{-3}$ & 6 & carbon \\
$\mathrm{Pt}_{n, \mathrm{Co}} / \alpha-\mathrm{Al}_{2} \mathrm{O}_{3}$ & $2 \times 10^{-3}$ & 6 & $\alpha$-alumina \\
$\mathrm{Pt}_{n, \mathrm{CO}} / \mathrm{C}$ & $3 \times 10^{-3}$ & 9 & carbon \\
$\mathrm{Pt}_{n, \mathrm{Co}} / \alpha-\mathrm{Al}_{2} \mathrm{O}_{3}$ & $3 \times 10^{-3}$ & 9 & $\alpha$-alumina
\end{tabular}

${ }^{a}$ Solvent, water/2-propanol (1/1); dose rate, $10 \mathrm{kGy} \cdot \mathrm{h}^{-1}$.

concentrations $\left[\mathrm{H}_{2} \mathrm{Pt}^{\mathrm{IV}} \mathrm{Cl}_{6}\right]=2 \times 10^{-3}$ or $3 \times 10^{-3} \mathrm{M}$ (Table 1). Indeed, in a previous paper, ${ }^{18}$ it was shown that under these conditions, Chini carbonyl clusters $(n \geq 7)$ are obtained at low doses until half of the $\mathrm{Pt}$ is reduced. The spectral shape change at higher doses attests to the conversion of the Chini clusters to larger carbonyl clusters $(2-3 \mathrm{~nm})$ ligated with some CO ligands denoted $\mathrm{Pt}_{n, \mathrm{CO}}$.

Pure grade reagents were purchased from Alfa (99.99\% purity $\mathrm{H}_{2} \mathrm{PtCl}_{6}$ ), Prolabo (2-propanol), and Air liquide (99.997\%, CO). The irradiation was carried out using a panoramic $260 \mathrm{TBq}$ ${ }^{60} \mathrm{Co} \gamma$-source at a dose rate of $10 \mathrm{kGy} \mathrm{h}^{-1}$. Doses used are listed in Table 1.

The assignment of the $\gamma$-synthesized clusters was based on previous data ${ }^{5,18,19}$ correlating the ultraviolet-visible (UV-vis) absorption with infrared (IR) spectra, which allowed the identification of the clusters.

Carbon powder (100 mg; Printex XE-2, BET surface area: $\left.975 \mathrm{~m}^{2} \mathrm{~g}^{-1}\right)$, which was freshly activated with $\mathrm{CO}_{2}\left(930{ }^{\circ} \mathrm{C}\right.$, $30 \mathrm{~min}$ ) or $100 \mathrm{mg}$ of $\alpha-\mathrm{Al}_{2} \mathrm{O}_{3}$ (Rhône-Poulenc, calcination at $750{ }^{\circ} \mathrm{C}, 6 \mathrm{~h}$ ), was introduced into the cluster solution after the radiolytic synthesis of the clusters. The volume of the solution was calculated to obtain a powder sample of $30 \mathrm{mg}$ of Pt charge on $100 \mathrm{mg}$ of carbon. The solution was stirred until the clusters adsorbed completely onto the support and the solution became colorless. The time required was largely dependent on the preparation conditions of the cluster and the nature of the support: the adsorption on carbon was completed within 15 min for Chini clusters, whereas $24 \mathrm{~h}$ were required for larger $\mathrm{CO}$ stabilized $\mathrm{Pt}$ clusters deposited on carbon $\left(\mathrm{Pt}_{n, \mathrm{CO}}\right)$. The adsorption on the $\alpha$-alumina was completed within only a few minutes.

After cluster deposition, the supported samples were filtered and washed by the same solvents as used for irradiation and allowed to dry, all operations being performed under $\mathrm{N}_{2}$ atmosphere for Chini clusters. For $\mathrm{Pt}_{n, \mathrm{CO}}$ clusters, which are stable in air, no particular caution was taken during the impregnation and drying processes. The powder was then pressed under 10 tons of charge to prepare tablets $(1 \mathrm{~cm}$ diameter, 1-2 mm thickness) for XAS investigation. These tablets were finally sealed with polyimide film under inert atmosphere in order to preserve their physicochemical integrity.

XAS Measurements. Data were collected at the LURE synchrotron facility in Orsay using the synchrotron radiation from the DCI storage ring running at $1.85 \mathrm{GeV}$, with an average current of $300 \mathrm{~mA}$. The EXAFS spectra were obtained on the EXAFS IV station with a double crystal Si(111) monochromator, in the transmission mode and using two ionization chambers as detectors. Energy calibration of the experiments was made with a Pt metal foil. EXAFS signals were measured at Pt $\mathrm{L}_{\mathrm{III}}$ edge (11564 eV).

Analysis. The formalism and analytical procedure used are standard ones using the EXAFS 95 soft ware. ${ }^{25}$ Fourier transforms (FT) were carried out for $k$-weighted EXAFS function $^{26} k \chi(k)$ over $2-13 \AA^{-1}$, with a Kaiser window 

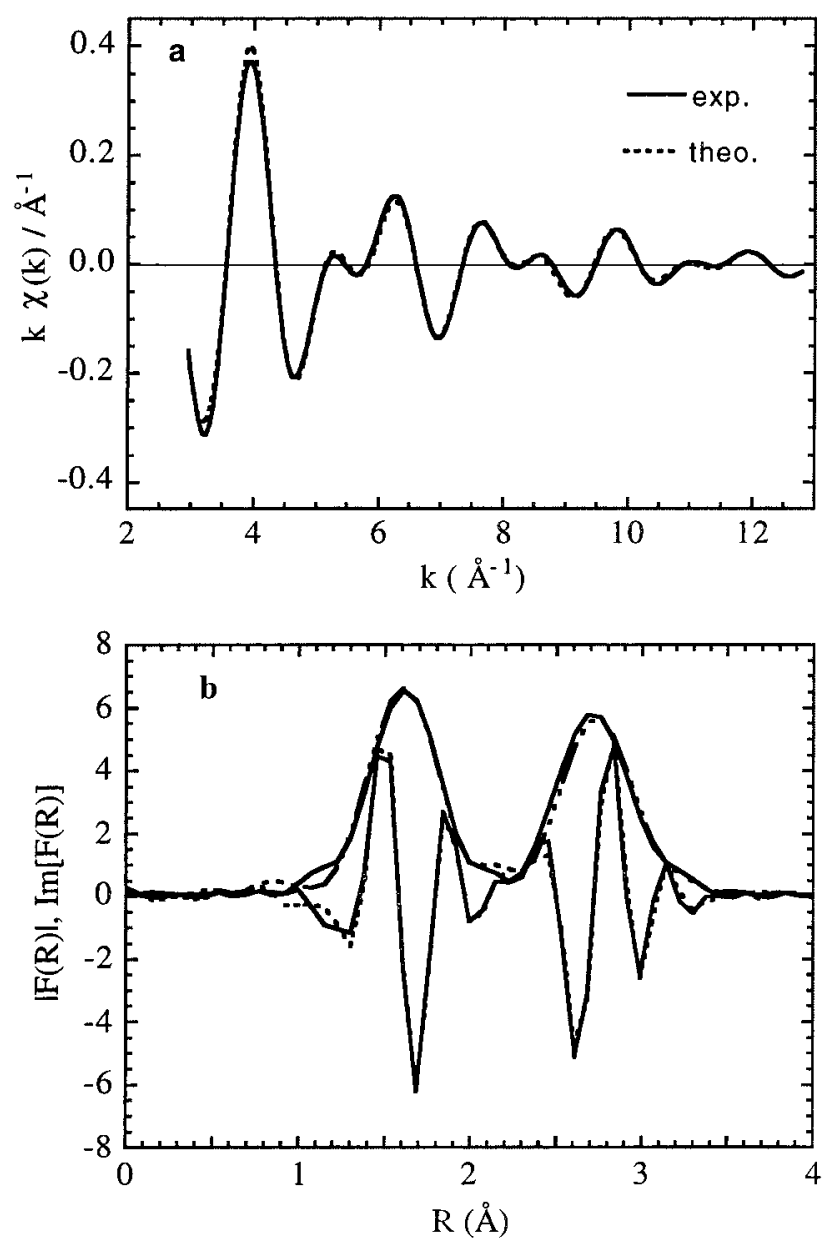

Figure 2. (a) EXAFS function and (b) FT modulus of $\mathrm{K}_{2} \mathrm{Pt}(\mathrm{CN})_{4}$. Full lines indicate experimental data and dotted lines theoretical data. Fourier transform was applied for $k \xi(k)$ over the range $2-13 \AA^{-1}$.

TABLE 2: Fitting Parameters for the Different Reference Compounds

\begin{tabular}{lcrccccc}
\hline \multicolumn{1}{c}{ compound } & shell & $N$ & $R(\AA)$ & $\sigma(\AA)$ & $\Gamma\left(\AA^{-2}\right)$ & $\Delta E(\mathrm{eV})$ & $\rho(\%)$ \\
\hline $\mathrm{Pt}$ metal & $\mathrm{Pt}$ & 12 & 2.76 & 0.07 & 0.71 & 6.0 & 0.6 \\
$\beta-\mathrm{PtO}_{2}$ & $\mathrm{O}$ & 6 & 2.02 & 0.07 & 0.54 & 8.1 & 1.0 \\
$\left.\mathrm{~K}_{2} \mathrm{Pt}_{(\mathrm{CN}}\right)_{4}$ & $\mathrm{C}$ & 4 & 1.98 & 0.05 & 0.32 & 6.8 & 2.1 \\
$\mathrm{KPt}_{2}(\mathrm{CN})_{4}, 3 \mathrm{H}_{2} \mathrm{O}$ & $\mathrm{C}$ & 4 & 1.96 & 0.05 & 0.32 & 6.7 & 1.5 \\
$\mathrm{~K}_{2} \mathrm{Pt}_{4}(\mathrm{CN})_{6}$ & $\mathrm{C}$ & 6 & 2.00 & 0.05 & 0.32 & 6.6 & 1.0
\end{tabular}

weighting function $(\tau=2.5)$. Choosing $n=1$ for the $k^{n} \chi(k)$ term allowed us to decrease the relative contribution of heavy atoms compared with that of the lighter atoms in the first shell around the absorbing one. Simulation was performed using theoretical scattering functions calculated with the code FEFF6. ${ }^{27}$ Platinum foil, $\mathrm{Pt}$ oxide $\left(\beta-\mathrm{PtO}_{2}\right)$, and three $\mathrm{Pt}$ cyanide complexes $\left[\mathrm{K}_{2} \mathrm{Pt}(\mathrm{CN})_{4}, \mathrm{KPt}_{2}(\mathrm{CN})_{4} \cdot 3 \mathrm{H}_{2} \mathrm{O}\right.$, and $\left.\mathrm{K}_{2} \mathrm{Pt}_{4}(\mathrm{CN})_{6}\right]$ were used as reference compounds. Fitting parameters $(N$, coordination number for absorber-backscatterer pair; $R$, absorber-backscatterer distance; $\sigma$, Debye-Waller factor; $\Delta E$, correction of threshold energy; $\rho$, residue value) for the references are listed in Table 2. Figure 2 shows comparisons between calculated and experimental EXAFS function and FT modules of $\mathrm{K}_{2} \mathrm{Pt}(\mathrm{CN})_{4}$.

Multiple Scattering Considerations. Because of the particular arrangement of the carbon and the oxygen atoms involved in the carbonyl clusters, we had to carefully analyze the second coordination of $\mathrm{Pt}$ atoms. To this purpose, we had to pay attention to multiple scattering processes of the photoelectron to check that they could not interfere in regions where we performed a single scattering analysis.
TABLE 3: Fitting Parameters for Chini Clusters $\left[\mathrm{Pt}_{3}(\mathrm{CO})_{6}\right]_{n}{ }^{2-}(n=4,5,6)$ Supported on Carbon under Nitrogen Atmosphere

\begin{tabular}{ccccccc}
\hline sample & $\begin{array}{c}\text { nature of } \\
\text { the shell }\end{array}$ & $N$ & $R(\AA)$ & $\sigma(\AA)^{a}$ & $\Delta E(\mathrm{eV})^{a}$ & $\rho(\%)$ \\
\hline$\left[\mathrm{Pt}_{3}(\mathrm{CO})_{6}\right]_{4}{ }^{2-} / \mathrm{C}$ & $\mathrm{C}$ & 1.5 & 1.92 & 0.05 & -1.3 & \\
& $\mathrm{Pt}$ & 3.5 & 2.68 & 0.07 & 0.6 & 0.7 \\
& $\mathrm{O}$ & 2.0 & 3.10 & 0.05 & -5.0 & \\
{$\left[\mathrm{Pt}_{3}(\mathrm{CO})_{6}\right]_{5}{ }^{2-} / \mathrm{C}$} & $\mathrm{C}$ & 1.3 & 1.92 & 0.05 & -1.1 & \\
& $\mathrm{Pt}$ & 4.5 & 2.68 & 0.06 & -0.4 & 0.9 \\
& $\mathrm{O}$ & 2.0 & 3.10 & 0.05 & -5.4 & \\
{$\left[\mathrm{Pt}_{3}(\mathrm{CO})_{6}\right]_{6}{ }^{2-} / \mathrm{C}$} & $\mathrm{C}$ & 1.3 & 1.92 & 0.06 & -1.7 & \\
& $\mathrm{Pt}$ & 4.5 & 2.68 & 0.06 & -0.1 & 0.9 \\
& $\mathrm{O}$ & 2.0 & 3.10 & 0.05 & -4.7 &
\end{tabular}

${ }^{a}$ Difference from the reference values.

TABLE 4: Fitting Parameters for Sample Exposed to Air Corresponding to Chini Clusters $\left[\mathrm{Pt}_{3}(\mathrm{CO})_{6}\right]_{n^{2-}}(n=4,5,6)$ Supported on Carbon

\begin{tabular}{ccccccc}
\hline sample & nature & $N$ & $R(\AA)$ & $\sigma(\AA)$ & $\Delta E(\mathrm{eV})^{a}$ & $\rho(\%)$ \\
\hline$\left[\mathrm{Pt}_{3}(\mathrm{CO})_{6}\right]_{4}{ }^{2-} / \mathrm{C}$ & $\mathrm{C}$ & 1.5 & 1.98 & 0.05 & -2.2 & 0.7 \\
& $\mathrm{O}$ & 1.5 & 2.05 & 0.04 & 0.6 & \\
& $\mathrm{Pt}$ & 1.5 & 2.60 & 0.07 & 3.0 & \\
{$\left[\mathrm{Pt}_{3}(\mathrm{CO})_{6}\right]_{5}{ }^{2-} / \mathrm{C}$} & $\mathrm{Pt}$ & 1.7 & 2.75 & 0.07 & 3.0 & \\
& $\mathrm{C}$ & 0.4 & 1.92 & 0.05 & -3.0 & 1.0 \\
& $\mathrm{Pt}$ & 4.3 & 2.67 & 0.07 & 1.3 & \\
{$\left[\mathrm{Pt}_{3}(\mathrm{CO})_{6}\right]_{6}{ }^{2-} / \mathrm{C}$} & $\mathrm{Pt}$ & 3.6 & 2.77 & 0.07 & 1.3 & \\
& $\mathrm{C}$ & 1.5 & 1.91 & 0.05 & 3.2 & 0.9 \\
& $\mathrm{Pt}$ & 5.0 & 2.63 & 0.07 & -3.7 & \\
& $\mathrm{Pt}$ & 4.0 & 2.76 & 0.06 & -3.7 &
\end{tabular}

${ }^{a}$ Difference from the reference values.

X-ray Diffraction. X-ray powder diffraction was recorded at the Institut Français du Pétrole by using Mo $\mathrm{K} \alpha$ radiation $(\lambda=0.7108 \AA)$ generated at $40 \mathrm{kV}$ and $40 \mathrm{~mA}$ on a vertical $\mathrm{X}$-ray diffractometer (Philips PW 1800). A typical scan speed of $0.02^{\circ} \mathrm{s}^{-1}$ was used for measurement.

\section{Results}

$\left[\mathrm{Pt}_{3}(\mathrm{CO})_{6}\right]_{n}{ }^{2-}$ Adsorbed on Carbon $(n=4-6)$. The modules of the FT, uncorrected from phase shift, for the different $\left[\mathrm{Pt}_{3}(\mathrm{CO})_{6}\right]_{n}{ }^{2-}(n=4-6)$ samples deposited on carbon are very similar (Figure 3). Two major peaks are observed. The first peak at the closest distance (not corrected from the phase shift) of $1.5 \AA$ is attributed to the bond with a light atom, (carbon or oxygen). Such a peak is also present in the reference $\mathrm{K}_{2} \mathrm{Pt}$ $(\mathrm{CN})_{4}$. The second main peak at $2.4 \AA$ is found to be the sum of several components, the major one arising from the existence of $\mathrm{Pt}-\mathrm{Pt}$ bonds at $2.68 \AA$. Noteworthy is that the distance at $3.0 \AA$ of the intertriangular $\mathrm{Pt}-\mathrm{Pt}$ distance is not observed. The fitting results and parameters given in Table 3 correspond to the signals between 1 and $3 \AA^{-1}$.

The modules of the FT of the different $\left[\mathrm{Pt}_{3}(\mathrm{CO})_{6}\right]_{n}{ }^{2-}(n=4$, $5,6)$ clusters supported on carbon and exposed to air after deposition are shown in Figure 4. Fitting parameters are listed in Table 4. The first peak at the shortest distance is associated with the presence of light atoms (carbon or oxygen) around $\mathrm{Pt}$ atoms, whereas the second one is related to a $\mathrm{Pt}-\mathrm{Pt}$ distance. The numerical simulation indicates that two families of $\mathrm{Pt}-\mathrm{Pt}$ bonds are measured. One $(2.60-2.67 \AA)$ is close to the value of the interatomic intratriangular $\mathrm{Pt}-\mathrm{Pt}$ distance present in the initial cluster $(R=2.66 \AA)$. The other one $(R=2.75-2.77 \AA)$ is close to the value associated with the Pt bulk compound $(R=2.77 \AA)$ and is probably due to the presence of small fcc Pt clusters inside the material. As in clusters under nitrogen 


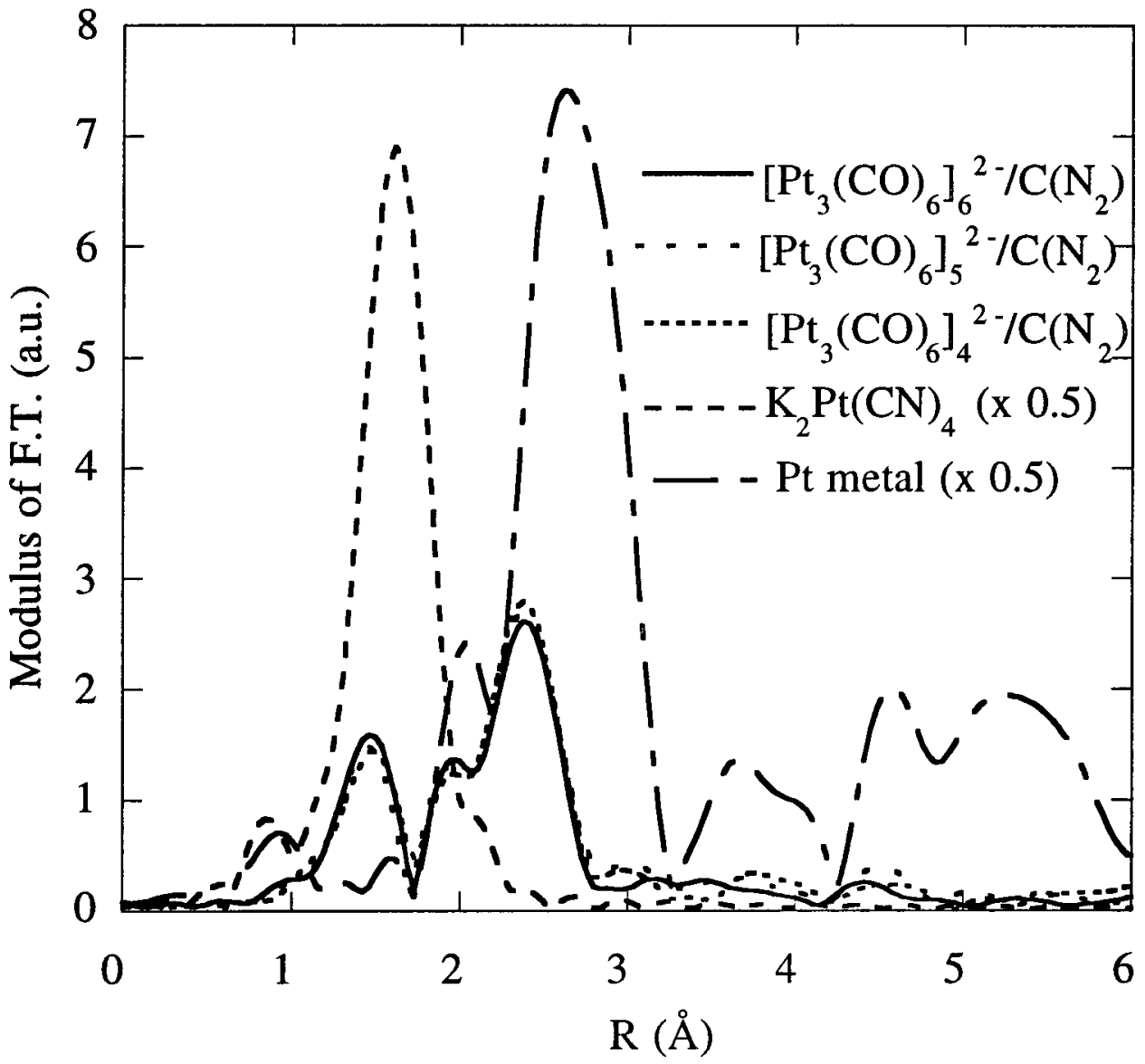

Figure 3. Modulus of the FT uncorrected for phase shift for $\left[\mathrm{Pt}_{3}(\mathrm{CO})_{6}\right]_{n}{ }^{2-}(n=4,5,6)$, deposited on carbon and kept under inert atmosphere support, compared with the FT modulus of reference compounds ( $\mathrm{Pt}$ metallic foil and $\left.\mathrm{K}_{2} \mathrm{Pt}(\mathrm{CN})_{6}\right)$.

TABLE 5: Fitting Parameters for $\mathbf{P t}_{n, \text { co }}$ Clusters Prepared at 2 and $3 \times 10^{-3} \mathrm{M}$ and Supported on Carbon Exposed to Air

\begin{tabular}{lcccccc}
\hline \multicolumn{1}{c}{ cluster } & $\begin{array}{c}\text { nature of } \\
\text { the shell }\end{array}$ & $N$ & $R(\AA)$ & $\sigma(\AA)$ & $\Delta E(\mathrm{eV})^{a}$ & $\rho(\%)$ \\
\hline $\mathrm{Pt}_{n, \mathrm{CO}}$ & $\mathrm{C}$ & 3.0 & 2.03 & 0.05 & -2.2 & 0.5 \\
$2 \times 10^{-3} \mathrm{M}$ & $\mathrm{Pt}$ & 0.7 & 2.60 & 0.06 & -0.6 & \\
& $\mathrm{Pt}$ & 1.0 & 2.76 & 0.06 & -0.6 & \\
& $\mathrm{Pt}$ & 0.9 & 3.00 & 0.06 & -0.6 & \\
$\mathrm{Pt}_{n, \mathrm{CO}}$ & $\mathrm{C}$ & 2.5 & 1.92 & 0.06 & -2.2 & 0.4 \\
$3 \times 10^{-3} \mathrm{M}$ & $\mathrm{Pt}$ & 1.0 & 2.61 & 0.07 & 0.1 & \\
& $\mathrm{Pt}$ & 1.9 & 2.75 & 0.07 & 0.1 & \\
& $\mathrm{Pt}$ & 0.4 & 3.00 & 0.07 & 0.1 &
\end{tabular}

${ }^{a}$ Difference from the reference values.

atmosphere, the distance at $3.0 \AA$ of the intertriangular $\mathrm{Pt}-\mathrm{Pt}$ distance is not found.

$\mathbf{P t}_{n, \text { Co }}$ Deposited on Carbon. Figure 5 shows the FT modules of samples corresponding to the clusters $\mathrm{Pt}_{n, \mathrm{CO}}$ prepared at higher Pt concentration and deposited on carbon. The most important contribution is positioned at $1.5 \AA$, with an amplitude similar to the amplitude relative to the reference $\mathrm{K}_{2} \mathrm{Pt}(\mathrm{CN})_{4}$. In addition, a small contribution is measured that is assigned to $\mathrm{Pt}-\mathrm{Pt}$ bonds. The fitting procedure gives three families of interatomic distances. Two of them $(R=2.60 \AA$ and $R=3.00 \AA)$ are respectively close to the values related to intra- and intertriangular $\mathrm{Pt}-\mathrm{Pt}$ distances of the Chini clusters, and the last one $(R=2.76 \AA)$, is close to the value of the $\mathrm{Pt}-\mathrm{Pt}$ distance that exists in the fcc bulk metal $(R=2.77 \AA)$. The major difference between the two samples comes from the number of $\mathrm{Pt}-\mathrm{Pt}$ neighbors at $2.76 \AA$. For the sample prepared at $2 \times$
TABLE 6: Fitting Parameters for Samples $\left[\mathrm{Pt}_{3}(\mathrm{CO})_{6}\right]_{6}{ }^{2-}$ and $\mathrm{Pt}_{n, \mathrm{co}}$ Deposited on Alumina and Exposed to Air

\begin{tabular}{lcccccc}
\hline \multirow{1}{*}{ sample } & $\begin{array}{c}\text { nature of } \\
\text { the shell }\end{array}$ & $N$ & $R(\AA)$ & $\sigma(\AA)$ & $\Delta E(\mathrm{eV})^{a}$ & $\rho(\%)$ \\
\hline$\left[\mathrm{Pt}_{3}(\mathrm{CO})_{6}\right]_{6}{ }^{2-} / \mathrm{Al}_{2} \mathrm{O}_{3}$ & $\mathrm{C}$ & 1.0 & 2.06 & 0.07 & -5.0 & 0.9 \\
& $\mathrm{Pt}$ & 3.5 & 2.65 & 0.06 & 0.6 & \\
& $\mathrm{Pt}$ & 3.4 & 2.74 & 0.06 & -2.4 & \\
& $\mathrm{O}$ & 1.9 & 2.96 & 0.07 & 3.0 & \\
$\mathrm{Pt}_{n, \mathrm{CO}}$ & $\mathrm{C}$ & 2.2 & 2.03 & 0.05 & -2.7 & 0.8 \\
$2 \times 10^{-3} \mathrm{M} / \mathrm{Al}_{2} \mathrm{O}_{3}$ & $\mathrm{Pt}$ & 0.9 & 2.60 & 0.07 & 0.3 & \\
& $\mathrm{Pt}$ & 5.0 & 2.73 & 0.06 & 0.3 & \\
$\mathrm{Pt}_{n, \mathrm{CO}}$ & $\mathrm{C}$ & 1.9 & 2.03 & 0.07 & -2.7 & 0.6 \\
$3 \times 10^{-3} \mathrm{M} / \mathrm{Al}_{2} \mathrm{O}_{3}$ & $\mathrm{Pt}$ & 1.1 & 2.60 & 0.07 & 0.4 & \\
& $\mathrm{Pt}$ & 5.0 & 2.74 & 0.07 & 0.4 &
\end{tabular}

${ }^{a}$ Difference from the reference values.

$10^{-3} \mathrm{M}$, a value of 1.0 is found for $N_{\mathrm{Pt}-\mathrm{Pt}}$, and for the cluster prepared at $3 \times 10^{-3} \mathrm{M}$, the corresponding coordination number is equal to 1.9 (see Table 5). The XRD profiles of $\mathrm{Pt}_{n, \mathrm{CO}}$ deposited on carbon shows diffraction peaks corresponding to fcc Pt crystal (see Figure 6).

Effect of the Support. To evaluate the possible effect of the support, two new series of samples were prepared on $\alpha$-alumina to be compared with the Chini cluster $\left[\mathrm{Pt}_{3}(\mathrm{CO})_{6}\right]_{6}{ }^{2-}$ and the $\mathrm{Pt}_{n, \mathrm{CO}}$ carbonyl clusters prepared at higher concentrations and deposited on carbon (Table 6). The modules of FT are shown in Figure 7. Compared with the carbon support, significant increases in $\mathrm{Pt}-\mathrm{Pt}$ contribution are observed on the $\alpha$-alumina support for both adsorbates, $\left[\mathrm{Pt}_{3}(\mathrm{CO})_{6}\right]_{6}{ }^{2-}$ and $\mathrm{Pt}_{n, \mathrm{CO}}$. It seems that adsorption on $\alpha$-alumina results in a more important dissociation of the $\mathrm{Pt}-\mathrm{CO}$ bond and favors $\mathrm{Pt}-\mathrm{Pt}$ bonding. 


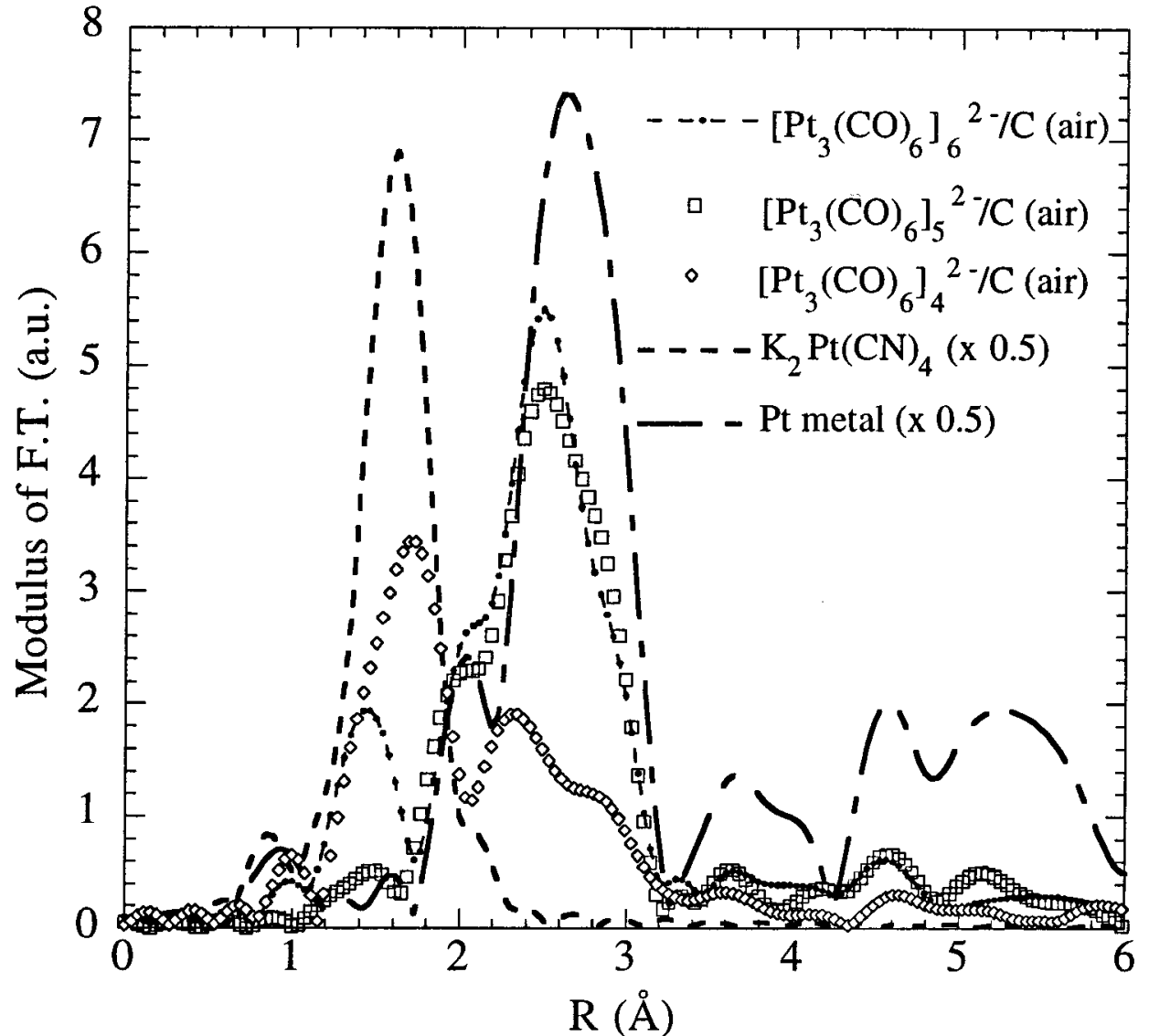

Figure 4. Modulus of the FT uncorrected for phase shift for $\left[\mathrm{Pt}_{3}(\mathrm{CO})_{6}\right]_{n}{ }^{2-}(n=4,5,6)$, deposited on the carbon support after an air exposure, compared with the FT modulus of reference compounds (Pt metallic foil and $\mathrm{K}_{2} \mathrm{Pt}(\mathrm{CN})_{6}$ ).

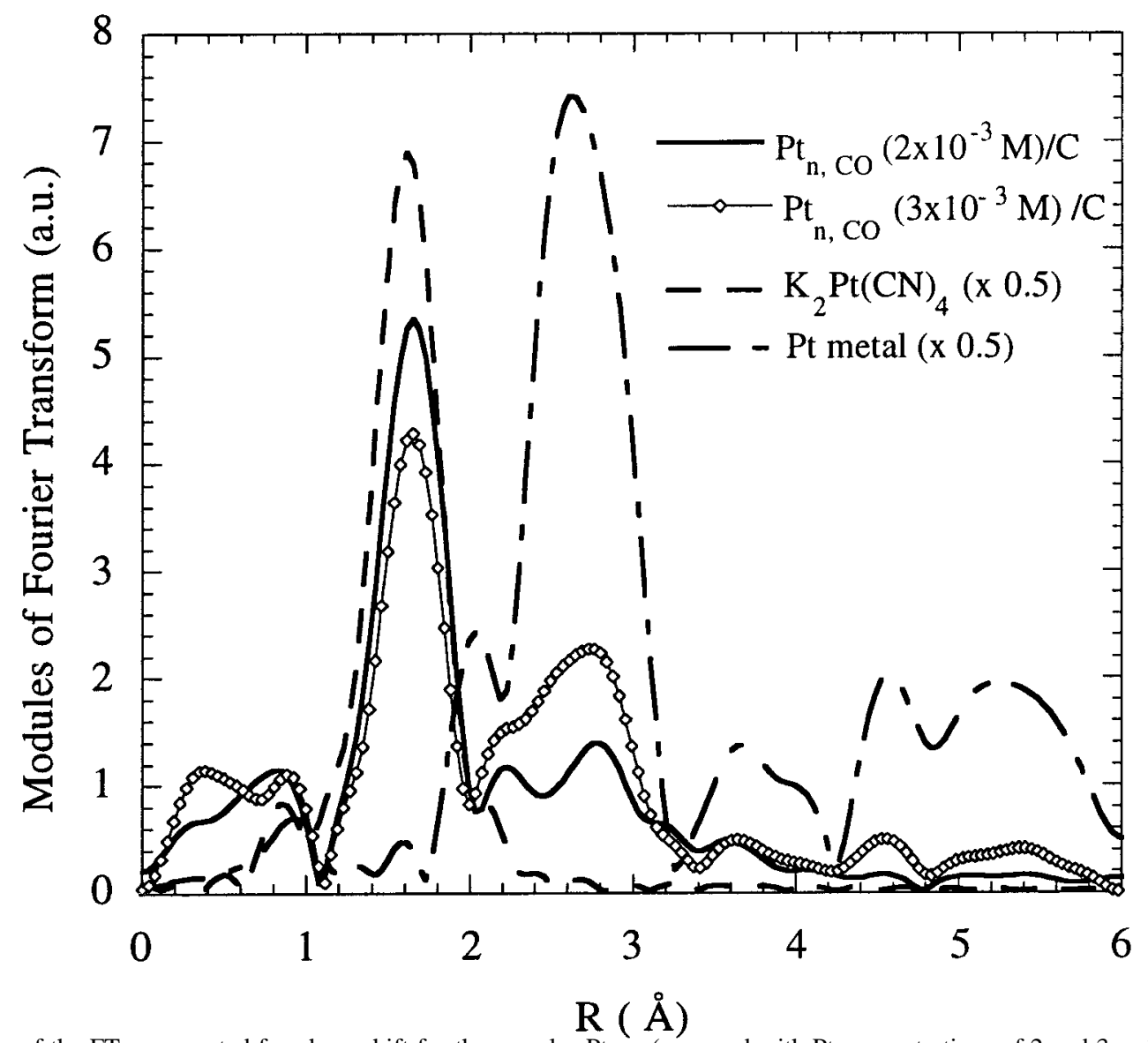

Figure 5. Modulus of the FT uncorrected for phase shift for the samples $\mathrm{Pt}_{n, \mathrm{CO}}$ (prepared with Pt concentrations of 2 and $3 \times 10^{-3} \mathrm{M}$ ) on carbon compared with the FT modulus of reference compounds (Pt metallic foil and $\mathrm{K}_{2} \mathrm{Pt}(\mathrm{CN})_{6}$ ). 


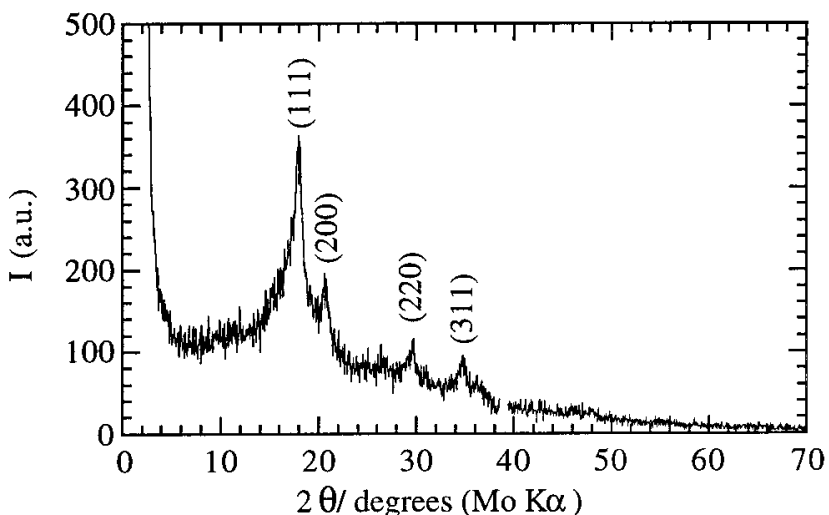

Figure 6. XRD profiles of $\mathrm{Pt}_{n, \mathrm{CO}}$ (prepared with $\mathrm{Pt}$ concentration of $\left.2 \times 10^{-3} \mathrm{M}\right)$ supported on carbon.

\section{Discussion}

The Nature of Adsorbed Chini-Type Clusters and Air Sensitivity. Under $\mathrm{N}_{2}$ atmosphere, the $\mathrm{Pt}-\mathrm{Pt}$ bulk distance $(2.77 \AA)$ is not observed for Chini clusters $\left[\mathrm{Pt}_{3}(\mathrm{CO})_{6}\right]_{n}{ }^{2-}(n=$ 4-6) deposited on carbon. Only a distance at 2.60-2.68 assigned to intratriangular $\mathrm{Pt}-\mathrm{Pt}$ distance is conserved (Table $3)$. Moreover, the average $\mathrm{Pt}$ neighbor number $(N=3.5$ for $\left[\mathrm{Pt}_{3}(\mathrm{CO})_{6}\right]_{4}{ }^{2-}$ or 4.5 for $\left.\left[\mathrm{Pt}_{3}(\mathrm{CO})_{6}\right]_{5-6}{ }^{2-}\right)$ obtained for this distance is larger than that existing in the Chini cluster $(N=$ 2.0), indicating that intertriangular $\mathrm{Pt}-\mathrm{Pt}$ bonds are broken. Only one type of distance $\mathrm{Pt}-\mathrm{C}(R=1.92 \AA)$ is obtained with $N=$ $1.5 \mathrm{C}$ neighbors per Pt atom. This result implies a partial loss of $\mathrm{CO}$ (terminal or doubly bonded) after the deposition on the carbon support. The $\mathrm{Pt}-\mathrm{C}$ carbon distance found is significantly shorter than the distance for bridging carbonyl group $(2.03 \AA)$ but larger than that for carbonyl terminal group (1.80 $\AA$ ) reported by Chini et al. ${ }^{4}$ Note that Ichikawa et al. ${ }^{14}$ obtained similar values as ours for terminal carbonyl $(\mathrm{Pt}-\mathrm{C}=1.90 \AA$ for $\left[\mathrm{Pt}_{3}(\mathrm{CO})_{6}\right]_{5}{ }^{2-} / \mathrm{NEt}_{4} \mathrm{Cl} / \mathrm{FSM}-16$ and $1.99 \AA$ for $\left[\mathrm{Pt}_{3}(\mathrm{CO})_{6}\right]_{4}{ }^{2-} /$ $\mathrm{NaY}$ zeolite) and found higher distances for bridging carbonyl (respectively, 2.08 and $2.14 \AA$ ). They have also shown that $\left[\mathrm{Pt}_{3}(\mathrm{CO})_{6}\right]_{5}{ }^{2-} / \mathrm{NEt}_{4} \mathrm{Cl} / \mathrm{FSM}-16$ was transformed by the controlled removal of $\mathrm{CO}$ (at $300-343 \mathrm{~K}$ ) into the partially decarbonylated $\mathrm{Pt}_{15}$ cluster with only $\mathrm{CO}$ terminal ligands.

Our results suggest a quite new arrangement of all the triangles on the support. The single distance $\mathrm{Pt}-\mathrm{Pt}$ with $N=$ 3.5-4.5 suggests that the triangles are conserved but that they are no longer stacked together. They are probably linked to the carbon surface in a planar monolayer. The $\mathrm{CO}$ bonds have been partially replaced by $\mathrm{C}$ bonds to the surface.

For $\left[\mathrm{Pt}_{3}(\mathrm{CO})_{6}\right]_{4}{ }^{2-}$, it is clear that a significant modification of the Pt environment occurs when the sample adsorbed on carbon is exposed to air (Tables 3 and 4). However, the distances $\mathrm{Pt}-\mathrm{Pt}$ of the intratriangular $\mathrm{Pt}-\mathrm{Pt}(2.60-2.68 \AA)$ are found in both cases, for the samples conserved under $\mathrm{N}_{2}$ or the samples exposed to air, but the bulk fcc distances Pt-Pt (2.77 ̊) are found only for the samples exposed to air. At the distance $2.77 \AA$, only a few Pt neighbors are present, suggesting that the particles are small. Therefore, after deposition on the carbon support, a residue of the Chini cluster still remains with other small $\mathrm{Pt}_{n}$ clusters.

For $\left[\mathrm{Pt}_{3}(\mathrm{CO})_{6}\right]_{5}{ }^{2-}$ and $\left[\mathrm{Pt}_{3}(\mathrm{CO})_{6}\right]_{6}{ }^{2-}$ samples also, a significant modification of the Pt environment occurs when the sample is exposed to air (Tables 3 and 4). The intratriangular $\mathrm{Pt}-\mathrm{Pt}$ distance of $2.66 \AA$ remains, but with more neighbors compared with the Chini clusters $(N=2)$. The bulk $\mathrm{Pt}-\mathrm{Pt}$ distance of $2.77 \AA$ is found, also with more Pt neighbors $(N=1.7)$ than for $\left[\mathrm{Pt}_{3}(\mathrm{CO})_{6}\right]_{4}{ }^{2-}$ on carbon. This result implies a growth of the clusters on the support, with an increasing number of $\mathrm{Pt}-$ $\mathrm{Pt}$ bonds after the contact with air. For oxidized $\left[\mathrm{Pt}_{3}(\mathrm{CO})_{6}\right]_{5}{ }^{2-}$ and $\left[\mathrm{Pt}_{3}(\mathrm{CO})_{6}\right]_{6}{ }^{2-}$ on carbon, values of $N$ obtained at the $\mathrm{Pt}-\mathrm{Pt}$ distances 2.66 and $2.77 \AA$, respectively, are much higher than those obtained with $\left[\mathrm{Pt}_{3}(\mathrm{CO})_{6}\right]_{4}{ }^{2-}$ on carbon, suggesting the presence of larger particles.

The sample $\left[\mathrm{Pt}_{3}(\mathrm{CO})_{6}\right]_{4}{ }^{2-}$ on carbon has a different behavior when exposed to air compared with the samples $\left[\mathrm{Pt}_{3}(\mathrm{CO})_{6}\right] 5^{2-}$ and $\left[\mathrm{Pt}_{3}(\mathrm{CO})_{6}\right]_{6}{ }^{2-}$ (Tables 3 and 4). In conclusion, this

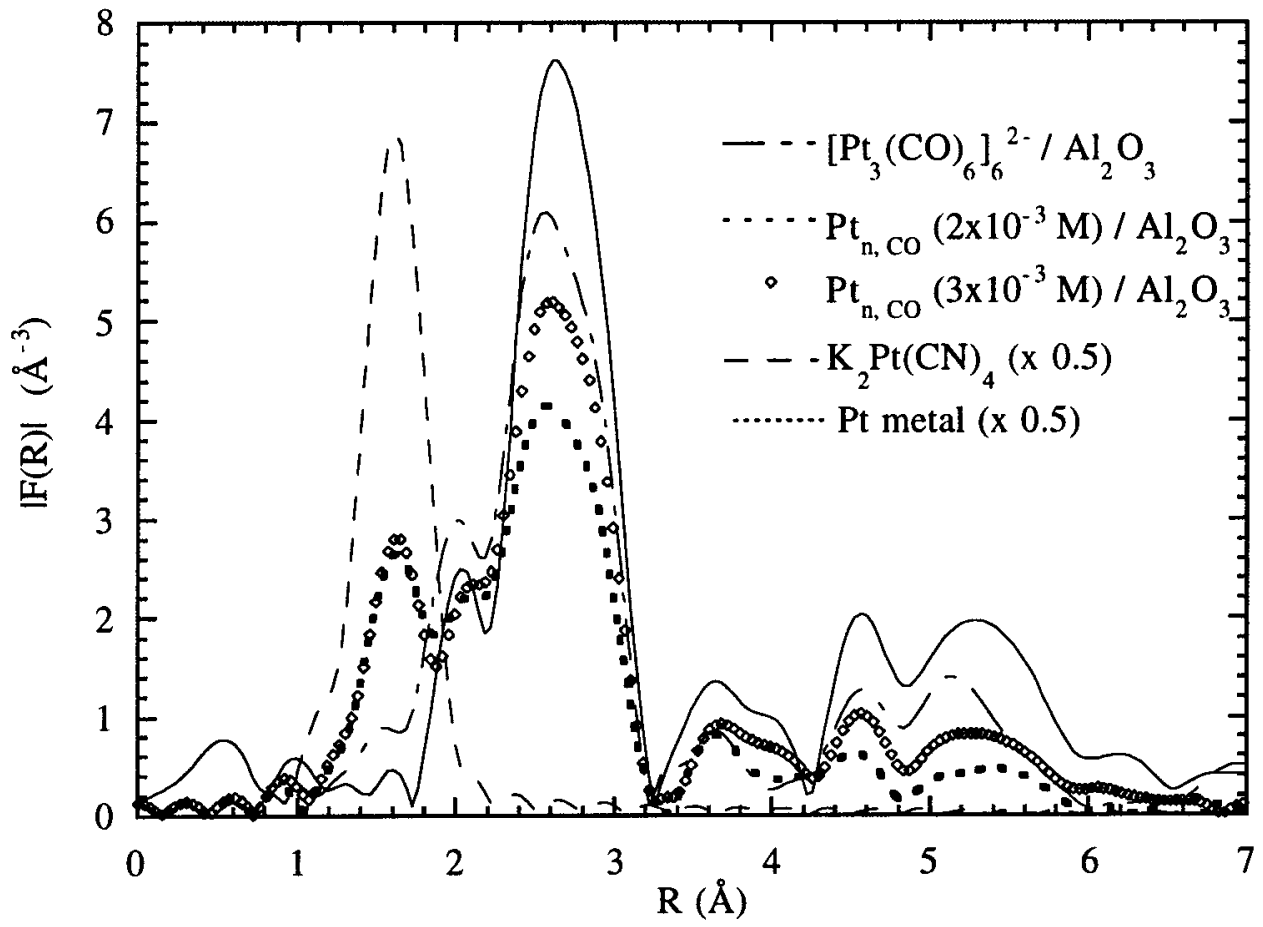

Figure 7. FT modules of $\left[\mathrm{Pt}_{3}(\mathrm{CO})_{6}\right]_{6}{ }^{2-}$ and $\mathrm{Pt}_{n, \mathrm{CO}}$ (prepared with Pt concentrations of 2 and $3 \times 10^{-3} \mathrm{M}$ ), deposited on alumina support, compared with the FT modulus of reference compounds (Pt metallic foil and $\mathrm{K}_{2} \mathrm{Pt}(\mathrm{CN})_{6}$ ). 
transformation seems to be less important for $\left[\mathrm{Pt}_{3}(\mathrm{CO})_{6}\right]_{4}{ }^{2-}$ than that occurring with oxidized samples of $\left[\mathrm{Pt}_{3}(\mathrm{CO})_{6}\right] 5^{2-}$ and $\left[\mathrm{Pt}_{3}(\mathrm{CO})_{6}\right]_{6}^{2-}$ adsorbed on carbon.

Structure of $\mathbf{P t}_{n, \mathrm{CO}}$ Clusters Adsorbed on Carbon. In Figure 5 , the moduli of FT of $\mathrm{Pt}_{n, \mathrm{CO}}$ (prepared with $2 \times 10^{-3}$ and $3 \times 10^{-3} \mathrm{M}$ ) deposited on carbon are plotted. In Table 5 are gathered the different results given by numerical simulations of the EXAFS modulations. The Pt-Pt intratriangular (2.66 $\AA$ ) and intertriangular $(3.0 \AA)$ distances that exist in the Chini clusters are still present, indicating that the Chini cluster shape is partially maintained. However, the $\mathrm{Pt}-\mathrm{Pt}$ bulk distance is also found, with $N=1.0$ and 1.9 for the clusters prepared at 2 and $3 \times 10^{-3} \mathrm{M}$, respectively, suggesting that the particles are larger in the latter case. Generally, the radiolytic synthesis of large aggregates is favored by an increase in the concentration of the precursor salt. At high salt concentrations, the distances between the nucleation centers decrease, favoring aggregation against ligation. Classical X-ray diffraction studies performed on these samples have shown that fcc Pt clusters containing $>100$ atoms are also present (Figure 6). Note that transmission electron microscope (TEM) observations have shown a size distribution (clusters of 1 to $5 \mathrm{~nm}$ and more) with a mean size of 1.5 and $2 \mathrm{~nm}$ for clusters deposited on carbon and prepared at 2 and $3 \times 10^{-3} \mathrm{M}$, respectively. ${ }^{19}$ The distance $R=2.03 \AA$, assigned to a $\mathrm{Pt}-\mathrm{C}$ bond, can be related either to the $\mathrm{Pt}-\mathrm{C}$ distance $(2.03 \AA$ in the Chini clusters for the bridged CO, due to the carbonyl ligand or the bond with the support) or to the $\mathrm{Pt}-\mathrm{O}$ distance $(2.04 \AA)$ that should be associated with an oxidation state of the Pt.

Effect of the Support. In Figure 7, the moduli of FT of $\mathrm{Pt}_{n, \mathrm{CO}}$ (prepared at 2 and $3 \times 10^{-3} \mathrm{M}$ ) deposited on alumina are plotted. The sample $\left[\mathrm{Pt}_{3}(\mathrm{CO})_{6}\right]_{6}{ }^{2-}$ on $\alpha$-alumina is constituted partly of Pt triangular units of the precursor, probably in a planar structure, and also of larger particles with the $\mathrm{Pt}-\mathrm{Pt}$ bulk distances. The $\mathrm{CO}$ ligands remain in part.

Table 6 shows that the $\mathrm{Pt}_{n, \mathrm{CO}}$ clusters grow on the alumina support to form small Pt particles: fcc $\mathrm{Pt}-\mathrm{Pt}$ bonds are found with low metal coordination. Nevertheless, some triangular units (with the $\mathrm{Pt}-\mathrm{Pt}$ intratriangular distances $=2.60 \AA$ ) still remain. The distance of $2.03 \AA$ is related to the $\mathrm{Pt}-\mathrm{C}$ bond due to the carbonyl ligand or to the $\mathrm{Pt}-\mathrm{O}$ distance.

These different sets of results show the possibility to discriminate the structures of carbonyl Pt clusters obtained through radiolytic synthesis and deposited on carbon or $\alpha$ alumina supports. In fact, at least two groups of Pt entities are generated, and their structural features as well as their contribution change with the preparation conditions and the support. The first group is still close to the clusters in solution. More particularly in the case of the carbon-deposited Chini clusters, this group is composed of triangular units ligated to $\mathrm{CO}$ ligands. The EXAFS analysis points out these phases through their specific values associated with the intra- and intertriangular $\mathrm{Pt}-$ Pt atomic distances equal to 2.60 and $3.00 \AA$, respectively. However, when supported, the triangular units can organize into a planar stucture, distorting the bonds between the triangles. The second group is constituted of small clusters with fcc structure for which the intermetallic $\mathrm{Pt}-\mathrm{Pt}$ distance is close to the bulk one.

\section{Conclusion}

We have studied by XAS the structure of the different Pt carbonyl clusters supported on carbon and $\alpha$-alumina that were previously found catalytically efficient in fuel cell reactions. ${ }^{19}$ From EXAFS at the Pt $\mathrm{L}_{\mathrm{III}}$ edge, it was found that the $\mathrm{Pt}$ carbonyl clusters undergo more or less strong deformation when deposited onto the support. On carbon support, some of the carbonyl groups still remain to be ligated to $\mathrm{Pt}$, but the intertriangular $\mathrm{Pt}-\mathrm{Pt}$ bond is lost. No significant difference was found in the FT modules for the Chini precursors $\left[\mathrm{Pt}_{3}(\mathrm{CO})_{6}\right]_{n}{ }^{2-}$ $(n=4,5,6)$ once deposited on the carbon support, and a planar structure such as suggested by the four neighbor Pt atoms in the coordination shell. In air, part of the deposited clusters are transformed into small fcc clusters for which the intermetallic $\mathrm{Pt}-\mathrm{Pt}$ distance is close to the bulk one. Nevertheless, this transformation is more important for $\left[\mathrm{Pt}_{3}(\mathrm{CO})_{6}\right]_{5}{ }^{2-}$ and $\left[\mathrm{Pt}_{3}(\mathrm{CO})_{6}\right]_{6}{ }^{2-}$ than for the deposited $\left[\mathrm{Pt}_{3}(\mathrm{CO})_{6}\right]_{4}{ }^{2-}$ clusters. For $\mathrm{Pt}_{n, \mathrm{CO}}$ clusters prepared at higher Pt concentration and deposited on carbon, a residue of the initial Chini stucture is still present among other clusters of fcc stucture. On $\alpha$-alumina support, the structural change is more important. The formation of larger fcc Pt clusters are obvious from FT moduli.

Acknowledgment. The authors thank Dr. E. Prouzet for very helpful discussions. The authors are grateful to Dr. B. Rebours (Institut Français du Pétrole) for XRD measurement and Dr. P. Parent for lending us Pt cyanides. Technical assistance of Dr. F. Villain and Mr. H. Sonneville is acknowledged.

\section{References and Notes}

(1) Watanabe, M.; Uchida, M.; Motoo, S. J. Electroanal. Chem. 1987, 229, 395 .

(2) Christensen, P. A.; Hammett, A.; Troughton, G. L. J. Electroanal. Chem. 1993, 362, 207.

(3) Méli, G.; Léger, J. M.; Lamy, C.; Durand, R. J. Appl. Electrochem. 1993, 23, 197.

(4) Calabrese, J. C.; Dahl, L. F.; Cavaliere, A.; Chini, P.; Longoni, G.; Martinengo, S. J. Am. Chem. Soc. 1974, 96, 2614.

(5) Longoni, G.; Chini, P. J. Am. Chem. Soc. 1976, 98, 7225.

(6) Chini, P. J. Organomet. Chem. 1980, 200, 37.

(7) Chang, K. W.; Wooley, R. G. J. Phys. C: Solid State Phys. 1979. 12,2745 .

(8) Underwood, D. J.; Hoffmann, R.; Tatsumi, K.; Nakamura, A.; Yamamoto, Y. J. Am. Chem. Soc. 1985, 107, 5968.

(9) Mealli, C. J. Am. Chem. Soc. 1985, 107, 2245

(10) De Mallmann, A.; Barthomeuf, D. Catal. Lett. 1990, 5, 213.

(11) Kubelková, L.; Drozdová, L.; Brabec, L.; Nováková, J.; Kotrla, J.; Hülstede, P.; Jaeger, N. I.; Schulz-Ekloff, G. J. Phys. Chem. 1996, 100, 15517.

(12) Li, G.-J.; Fujimoto, T.; Fukuoka, A.; Ichikawa, M. J. Chem. Soc., Chem. Commun. 1991, 1337.

(13) Li, G.-J.; Fujimoto, T.; Fukuoka, A.; Ichikawa, M. Catal. Lett. 1992, 12,171 .

(14) Yamamoto T.; Shido T.; Inagaki S.; Fukushima Y.; Ichikawa M. J. Phys. Chem., 1998, 102, 3866.

(15) Sasaki M.; Osada M.; Higashimoto N.; Yamamoto T.; Fukuaka A.; Ichikawa, M. J. Mol. Catal. 1999, 141, 223.

(16) Lewis, G. J.; Roth, J. D.; Montag, R. A.; Safford, L. K.; Gao, X.; Chang, S.-C.; Dahl, L. F.; Weaver, M. J. J. Am. Chem. Soc. 1990, 112, 2831.

(17) Roth, J. D.; Lewis, G. J.; Safford, L. K.; Jing, X.; Dahl, L. F.; Weaver, M. J. J. Am. Chem. Soc. 1992, 114, 6159.

(18) Le Gratiet, B.; Remita, H.; Picq, G.; Delcourt, M.-O. Radiat. Phys. Chem. 1996, 47, 263.

(19) Le Gratiet, B.; Remita, H.; Picq, G.; Delcourt, M.-O. J. Catal. 1996, 164,36 .

(20) Stern, E. A.; Sayers, D. E.; Lytle, F. W. Phys. Rev. B. 1975, 11, 4836.

(21) Bazin, D.; Sayers, D.; Rher, J. J. Phys. Chem. B. 1997, 101, 11040.

(22) Mansour, A. N.; Cook, Jr. J. W.; Sayers, D. E. J. Phys. Chem. 1984, $88,2330$.

(23) The Study of Fast Processes and Transient Species by Electron Pulse Radiolysis, NATO ASI, Baxendale, J. H., Busi, F., Eds.; Vol. 86; Reidel: Dordrecht, 1981.

(24) Freeman, G. R. NSRDS-NBS 1974, 4, 8.

(25) Michalowicz, A. Logiciels pour la Chimie, Société Française de Chimie: Paris, 1991

(26) Akura, K. In X-ray Absorption Fine for Catalysts and Surfaces; Iwasawa, I., Ed.; World Scientific: River Edge, NJ, 1996; p 40.

(27) Rehr, J. J.; Mustre de Leon, J.; Zabinsky, S. I.; Albers, R. C. J. Am. Chem. Soc. 1991, 113, 5135. 